\title{
Avaliação de um controle estratégico da artrite encefalite caprina em rebanho caprino leiteiro
}

[Evaluation of strategic control of caprine arthritis- encephalitis in dairy herd goats]

A.S. Rodrigues ${ }^{1}$, R.R. Pinheiro ${ }^{2}$, R.L.L. Brito ${ }^{3}$, A. Andrioli ${ }^{2}$, E.L. Oliveira ${ }^{2}$, L.H. Sider ${ }^{2}$, V.W. Santos ${ }^{4}$, L.S. Oliveira ${ }^{2}$, R.P. Dias ${ }^{1}$, A.M.G. Gouveia ${ }^{5}$, M.F.S. Teixeira ${ }^{1 *}$

${ }^{1}$ Universidade Estadual do Ceará - Fortaleza, CE

${ }^{2}$ Empresa Brasileira de Pesquisa Agropecuária - Embrapa Caprinos e Ovinos - Sobral, CE

${ }^{3}$ Instituto Superior de Teologia Aplicada - Sobral, CE

${ }^{4}$ Universidade Federal Rural do Semiárido - Mossoró, RN

${ }^{5}$ Universidade Federal de Minas Gerais - Belo Horizonte, MG

\begin{abstract}
RESUMO
O objetivo deste trabalho foi avaliar a utilização periódica de testes de diagnóstico mais sensíveis aliados às práticas de manejo, visando ao controle eficaz da artrite encefalite caprina (CAE). Foram realizadas oito coletas de sangue em matrizes e reprodutores. Da primeira à sétima análise, as coletas foram quadrimestrais, utilizando-se os testes de imunodifusão em gel de agarose (IDGA), ensaio imunoenzimático indireto (ELISA-i) e Western Blot (WB). A oitava coleta aconteceu seis meses após a sétima, utilizando-se o WB e a reação em cadeia de polimerase (PCR). A prevalência da CAE foi de $6,8 \%, 14,9 \%$ e $39,2 \%$ no IDGA, ELISA-i e WB, respectivamente. Na última análise, foram detectados $0,9 \%$ de animais positivos pelo WB e $10,8 \%$ pela PCR. Apesar de não erradicarem a CAE, as medidas adotadas, aliadas à utilização periódica dos testes sorológicos e à combinação com a PCR, foram importantes para reduzir significativamente os animais soropositivos no rebanho.
\end{abstract}

Palavras-chave: ELISA, IDGA, lentivírus de pequenos ruminantes, Western Blot

\begin{abstract}
The aim of this study was to evaluate the periodic use of more sensitive diagnostic tests associated to management practices for the effective control of caprine arthritis-encephalitis (CAE). We carried out eight blood samples in does and bucks. From the first to the seventh analysis, the samples were quarterly, using Agarose Gel Immunodiffusion (AGID), Enzyme linked immunosorbent assay (i-ELISA) and Western Blot (WB) tests. The eighth collection was made six months after the seventh, using the WB and Polymerase Chain Reaction (PCR). The prevalence of CAE was 6.8\%, 14.9\% and 39.2\% in the AGID, $i-$ ELISA and WB respectively. The last analysis detected $0.9 \%$ of animals positive by WB and $10.8 \%$ by PCR. Although they do not eradicate CAE, steps taken together with the periodic use of serological tests and the combination with PCR were important to significantly reduce positive animals in the herd.
\end{abstract}

Keywords: AGID, ELISA, small ruminant lentivirus, western blot

\section{INTRODUÇÃO}

Caprinos de qualquer raça, sexo e faixa etária podem ser infectados pelo vírus da artrite encefalite caprina (CAEV), cujo período de incubação varia de meses a anos (Dawson, 1989). É indicativa de infecção a presença de

Recebido em 19 de outubro de 2016

Aceito em 3 de abril de 2017

*Autor para correspondência (corresponding author)

E-mail: labovirfavetuece@uece.br lesões na articulação, no pulmão, no sistema nervoso e na glândula mamária. Todavia, em muitos casos, essa doença pode ser assintomática e os animais portadores do vírus se tornam fonte de infecção (Gregory et al., 2011).

Martínez-Navalón et al. (2013) observaram que, em estudo retrospectivo realizado com 4543 
cabras de 22 rebanhos leiteiros, animais soropositivos tinham lactações mais curtas e menor produção leiteira em comparação aos animais soronegativos. $\mathrm{O}$ leite apresentava menor teor de gordura, lactose e sólidos totais e maior contagem de células somáticas. Segundo Carneiro (2011), essa enfermidade predispõe, ainda, os animais à verminose gastrintestinal por Haemonchus spp., elevando o número de vermifugações necessárias para seu controle em até $70 \%$, principalmente em matrizes primíparas.

A infecção de crias por meio do colostro e leite de animais infectados torna a via digestiva a principal fonte de transmissão natural do CAEV (Lamara et al., 2001). Além desta, outras formas de transmissão por secreções salivares, respiratórias, intrauterina e sexual têm sido estudadas (Peterhans et al., 2004; Souza et al., 2013).

Por não haver tratamento nem vacinas eficazes contra o vírus, a eficiência dos programas sanitários de controle da CAE depende de vários fatores, dentre eles: práticas de manejo sanitário adequadas que visem à prevenção da transmissão pelo colostro e leite; boa sensibilidade e especificidade dos testes utilizados no diagnóstico inicial; além da frequência de utilização dos testes no monitoramento sorológico (Pinheiro et al., 2010).

Dentre as técnicas sorológicas existentes para o diagnóstico da CAE, a mais rotineiramente utilizada é a imunodifusão em gel de agarose (IDGA), atualmente recomendada pela Organização Mundial de Saúde Animal (OIE). É considerada uma técnica de fácil aplicação e alta especificidade, indicada como teste de triagem para essa enfermidade. No entanto, possibilita a permanência de caprinos infectados no rebanho por detectar somente altos níveis de anticorpos. Quando a IDGA é utilizada em programas de controle da $\mathrm{CAE}$, não proporciona ao produtor confiabilidade nos resultados dos verdadeiros negativos. Para esse propósito, é necessário que sua utilização seja empregada juntamente com outros testes mais sensíveis (Konishi et al., 2011), como o ensaio imunoenzimático indireto (ELISA-i) ou o Western Blot (WB), além da combinação com técnicas diretas, como a reação em cadeia de polimerase (PCR).
Este estudo teve como objetivo aplicar periodicamente, em um rebanho caprino leiteiro, testes de diagnósticos mais sensíveis, aliados às medidas de manejo, visando a um controle eficaz da CAE.

\section{MATERIAL E MÉTODOS}

O experimento foi conduzido na Embrapa Caprinos e Ovinos, localizada no município de Sobral, em uma região semiárida do sertão cearense, a $3^{\circ} 42^{\prime}$ de latitude Sul e $40^{\circ} 21^{\prime}$ de longitude Oeste e 83 metros de altitude. Este estudo recebeu a aprovação da Comissão de Ética no Uso de Animais da Universidade Estadual Vale do Acaraú (Ceua/UVA), sob o número 014/12.

Foram utilizados 281 caprinos, matrizes e reprodutores, sendo realizada pesquisa de anticorpos séricos antivírus da CAE pelas técnicas de IDGA, ELISA-i e WB. Os animais foram submetidos a oito coletas de sangue, e, à medida que eram diagnosticados animais soropositivos, estes eram segregados, segundo os resultados do WB, e já não participavam da próxima coleta. As sete primeiras coletas foram quadrimestrais, nas quais se utilizaram os testes de IDGA, ELISA-i e WB. A oitava coleta aconteceu seis meses após a sétima, utilizando-se o exame sorológico WB, associado a uma técnica molecular, a PCR nested, para detecção do DNA proviral do CAEV no sangue.

O rebanho leiteiro utilizado era constituído de animais das raças Anglo-Nubiana e Saanen, com idade entre um e seis anos, criados semiintensivamente e ordenhados mecanicamente sob linha de ordenha.

Diversas medidas de manejo, descritas a seguir, foram implantadas. As cabras eram divididas em grupos, de forma que ocorressem três parições por ano, para que não houvesse intermitência na produção de leite. A cobertura adotada era monta natural controlada, em que cabras soronegativas eram cobertas por reprodutores soronegativos e cabras soropositivas, por reprodutores soropositivos. O diagnóstico de gestação era realizado aos 45 dias, com auxílio do ultrassom. A limpeza da instalação era feita diariamente, e a cada 15 dias aplicava-se vassoura de fogo. A ordenha realizada era de forma mecânica, uma vez ao dia, de modo que se ordenhavam primeiro 
as fêmeas do grupo soronegativo, seguindo linha de ordenha. Após a ordenha, todos os equipamentos eram higienizados. Empregou-se, também, controle de fômites, como desinfecção de tatuadores e utilização de agulhas descartáveis. A fim de evitar transmissão pelo colostro e pelo leite, as crias eram separadas de suas mães imediatamente após o nascimento e transferidas para outra instalação, onde recebiam colostro termizado $\left(56^{\circ} \mathrm{C}\right.$, por uma hora $)$ e, posteriormente, leite pasteurizado. Houve a adição de novos animais no rebanho, contudo estes foram submetidos a um período de quarentena, no qual, em cada animal, eram realizados dois testes de IDGA e WB, em um intervalo de 60 dias. Da primeira à quinta coleta, não houve introdução de novos animais.

De 1994 a 2008, esse rebanho foi submetido ao programa de controle da CAE, com diagnóstico da enfermidade sendo realizado somente pela prova de IDGA com kit comercial americano (Caprine Arthritis-Encephalitis/Ovine Progressive Pneumonia Antibody test Kit Veterinary Diagnostic Technology, Inc ${ }^{\circledR}$, USA). Posteriormente, esse kit foi substituído pelo desenvolvido pela Embrapa Caprinos e Ovinos, seguindo-se protocolo empregado por Pinheiro et al. (2006). Essa técnica sorológica era realizada a cada seis meses e, de acordo com os resultados, os animais soropositivos eram separados do grupo dos soronegativos, sendo substituídos conforme os critérios de descarte adotados para sistema de criação de caprinos (Relatório..., 1996).

As coletas de sangue foram realizadas mediante punção da veia jugular, em tubo tipo Vacutainer ${ }^{\circledR}$ sem anticoagulante para os exames sorológicos, e com anticoagulante (EDTA) para a PCR nested. Na realização das sorologias, foi utilizado antígeno derivado de cultivos secundários de células de membrana sinovial caprina, infectadas pela estirpe padrão CAEV-Cork, preparado segundo metodologia de Pinheiro et al. (2006).

A microtécnica de IDGA e a técnica ELISA-i foram realizadas de acordo com a metodologia descrita por Pinheiro et al. (2006), e o teste de WB seguiu o protocolo de Rodrigues et al. (2014).

Para a detecção do DNA proviral do CAEV, foi realizada a PCR nested (PCRn). Para amplificação do gen gag CAEV Cork mediante PCR (Saltarelli et al., 1990), foram utilizados os primers 11 CAAGCAGCAGGAGGGAGAAGCTG- 3', nucleotídeos 953 a 975) e 2 (5'TCCTACCCCCATAATTTGATCCAC -3', nucleotídeos 1249 a 1226), descritos por Barlough et al. (1994), resultando na amplificação de um fragmento de DNA de $297 \mathrm{pb}$. A reação foi realizada segundo metodologia descrita por Andrioli et al. (2006).

Todos os dados foram tabulados no programa Excel $^{\circledR}$ e analisados estatisticamente no programa EPI Info ${ }^{\mathrm{TM}}$ 7.0. Calcularam-se a sensibilidade, a especificidade, o valor preditivo positivo, o valor preditivo negativo e o índice Kappa (concordância entre os dois testes) dos testes, por meio do programa Winepiscope 2.0.

\section{RESULTADOS}

O número de animais que participaram do estudo foi de 281, nos quais foi realizado um total de 511 testes sorológicos nos sete primeiros meses. $\mathrm{Na}$ oitava coleta, somente o método sorológico WB foi utilizado associado à PCR em 111 animais restantes. Alguns permaneceram sempre negativos e foram testados oito vezes, enquanto outros, recém- introduzidos, foram testados somente uma vez (Tab. 1).

Em valores percentuais, o WB foi o teste sorológico responsável pela maior detecção de soropositivos desde a primeira até a sexta coleta, havendo apenas um caso de superioridade do ELISA-i na sétima coleta. Nas coletas cinco e seis, somente o WB identificou anticorpos antiCAEV. O teste molecular PCR, utilizado na oitava e na última coleta, constatou $10,8 \%$ de positividade no rebanho, contra $0,9 \%$ detectada pelo WB (Fig. 1). 


\section{Rodrigues et al.}

Tabela 1. Resultado do diagnóstico da CAE pelos testes de IDGA, ELISA-i e WB, em coletas quadrimestrais, finalizando com testes de PCR e de WB, em rebanho caprino leiteiro criado em sistema semi-intensivo, no semiárido nordestino

\begin{tabular}{|c|c|c|c|c|c|c|c|c|c|c|c|c|c|c|c|c|c|c|c|c|c|c|c|}
\hline & \multicolumn{3}{|c|}{$l^{\mathrm{a}}$ coleta } & \multicolumn{3}{|c|}{$2^{a}$ coleta } & \multicolumn{3}{|c|}{$3^{a}$ coleta } & \multicolumn{3}{|c|}{$4^{2}$ coleta } & \multicolumn{3}{|c|}{$5^{a}$ coleta } & \multicolumn{3}{|c|}{$6^{\mathrm{a}}$ coleta } & \multicolumn{3}{|c|}{$7^{7}$ coleta } & \multicolumn{2}{|c|}{$8^{\mathrm{a}}$ coleta } \\
\hline & IDGA & ELISA & WB & IDGA & ELISA & WB & IDGA & ELISA & WB & IDGA & ELISA & WB & IDGA & ELISA & WB & IDGA & ELISA & WB & IDGA & ELISA & WB & WB & PCR \\
\hline POS & 10 & 22 & 58 & 0 & 3 & 12 & 0 & 3 & 10 & 1 & 2 & 4 & 0 & 0 & 2 & 0 & 0 & 1 & 1 & 2 & 1 & 1 & 12 \\
\hline NEG & 138 & 126 & 90 & 89 & 86 & 77 & 62 & 59 & 52 & 45 & 44 & 42 & 34 & 34 & 32 & 54 & 54 & 53 & 77 & 76 & 77 & 110 & 99 \\
\hline TOTAL & 148 & 148 & 148 & 89 & 89 & 89 & 62 & 62 & 62 & 46 & 46 & 46 & 34 & 34 & 34 & 54 & 54 & 54 & 78 & 78 & 78 & 111 & 111 \\
\hline
\end{tabular}

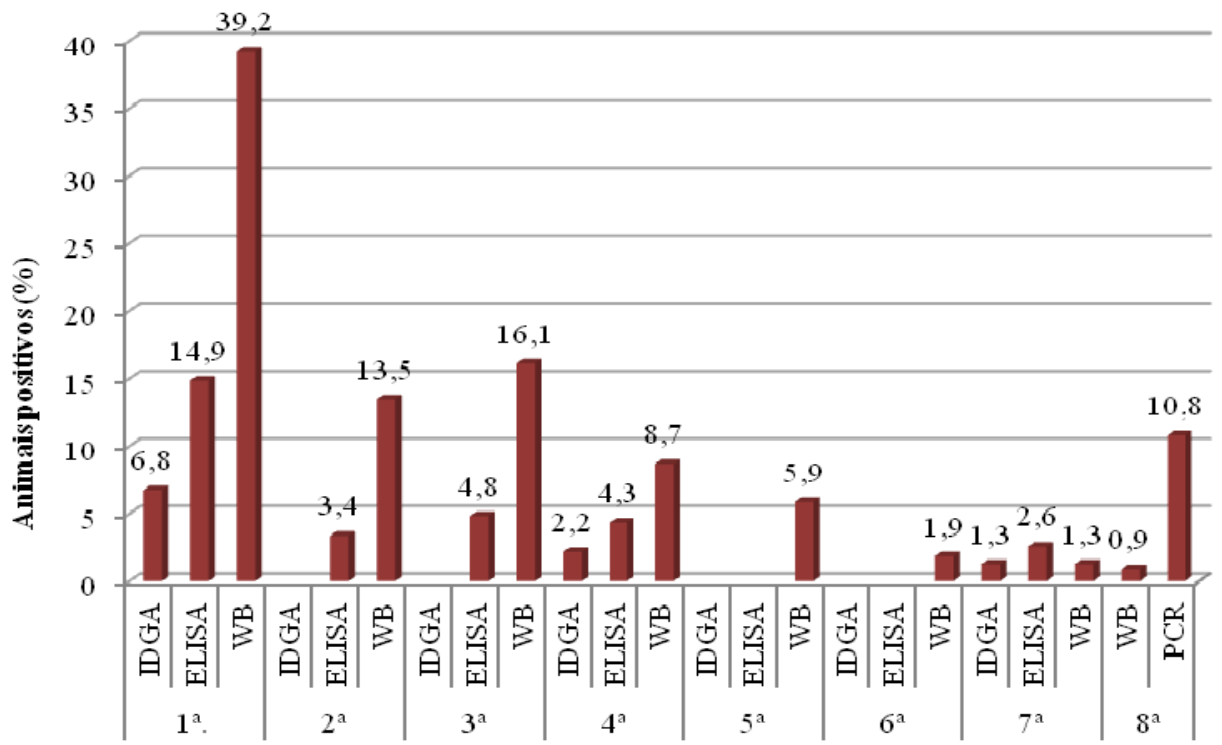

$\operatorname{PQS} \%$

\section{Testes de diagnóstico}

Figura 1. Percentual de animais soropositivos para CAE detectados pelos testes de IDGA, ELISA-i, e $\mathrm{WB}$, em coletas quadrimestrais, finalizando com testes de PCR e de WB, em rebanho caprino leiteiro criado em sistema semi-intensivo, no semiárido nordestino.

$\mathrm{O}$ WB foi o teste sorológico mais efetivo no diagnóstico da CAE, de forma que dos 511 testes realizados no programa de controle, $88(17,2 \%)$ foram positivos por essa técnica, seguida do ELISA-i com 32 detecções $(6,3 \%)$ e do IDGA com 12 detecções $(2,3 \%)$. Na Tab. 2, estão apresentados os resultados individuais dos testes quadrimestrais pela IDGA, pelo ELISA-i e pelo WB no diagnóstico da CAE e suas porcentagens.
A IDGA e o ELISA-i tiveram os valores de sensibilidade (Sens), especificidade (Espec), valor preditivo positivo (VPP), valor preditivo negativo (VPN), eficiência (Efic), índice Kappa e qui-quadrado $(\chi 2)$ estimados em relação ao $\mathrm{WB}$, com base nos resultados das sete primeiras coletas (Tab. 3).

Tabela 2. Resultados sorológicos da CAE pelos testes de IDGA, ELISA-i e WB em coletas quadrimestrais, em rebanho caprino leiteiro criado em sistema semi-intensivo, no semiárido nordestino

\begin{tabular}{cccccc|}
\hline & Pos & $\%$ & Neg & $\%$ & Total \\
WL & 88 & 17,2 & 423 & 82,8 & 511 \\
ELISA-i & 32 & 6,3 & 479 & 93,7 & 511 \\
IDGA & 12 & 2,3 & 499 & 97,7 & 511 \\
\hline
\end{tabular}


Tabela 3. Valores estimados de sensibilidade (Sens), especificidade (Espec), valor preditivo positivo (VPP), valor preditivo negativo (VPN), eficiência (Efic), índice Kappa e qui-quadrado ( $\chi 2$ ) para IDGA e ELISA-i, em relação ao WB de 511 amostras sorológicas de rebanho caprino leiteiro, criado em sistema semi-intensivo, no semiárido nordestino

\begin{tabular}{cccccccc|}
\hline Teste & Sens & Espec & VPP & VPN & Efic & Kappa & $\chi 2^{*}$ \\
\hline IDGA & 13,6 & 100,0 & 100,0 & 84,8 & 85,1 & 0,21 & $138,16(\mathrm{P}<0,001)$ \\
ELISA-i & 34,0 & 99,1 & 88,2 & 87,8 & 91,7 & 0,44 & $102,53(\mathrm{P}<0,001)$ \\
\hline
\end{tabular}

*Qui-quadrado com correção de Yates.

\section{DISCUSSÃO}

Na determinação da prevalência do rebanho no primeiro mês, observou-se que dos 148 animais, $10(6,8 \%)$ apresentaram anticorpos anti-CAEV pela IDGA, 22 (14,9\%) pelo ELISA-i e 58 $(39,2 \%)$ pelo WB. O WB foi o teste que apresentou maior percentual de soropositividade na primeira coleta, e, por ser considerado um teste de alta sensibilidade e especificidade (Zanoni et al., 1989; Pinheiro et al., 2012; Rodrigues et al., 2014), o resultado dele foi adotado como base para a separação dos animais em grupos soropositivo e soronegativo, sendo mantido esse critério nas demais coletas.

Das 136 matrizes, nove apresentaram anticorpos anti-CAEV na IDGA, 21 no ELISA-i e 54 no WB. Apesar de essa enfermidade afetar animais de todos os tipos raciais, é bastante documentada nas raças leiteiras (Moura Sobrinho et al., 2010).

Devido ao monitoramento periódico anteriormente adotado nesse rebanho, utilizando a técnica de IDGA, os resultados de prevalência achados na primeira coleta foram inferiores aos que geralmente são encontrados em rebanhos caprinos leiteiros infectados que não são submetidos a controle. Melo e Franke (1997), ao analisarem rebanhos leiteiros, pela IDGA, provenientes da microrregião de Fortaleza, no estado do Ceará, verificaram soroprevalência de 40,7\%, enquanto Madureira e Gomes (2007), no interior de São Paulo, observaram 34,93\%.

Ao se analisar a evolução do programa, desde a prevalência até a sexta coleta, notou-se que houve uma redução significativa $(\mathrm{P}<0,05)$ na incidência, principalmente quando foram considerados os resultados da IDGA e do ELISA-i. Por meio da técnica de IDGA, observou-se que, em dois momentos, $100 \%$ dos animais apresentaram resultado negativo em duas coletas consecutivas (segunda e terceira; quinta e sexta). Mediante a utilização do ELISAi, não foram verificados animais soropositivos na quinta e na sexta coletas. Apesar de existirem animais positivos nas duas últimas coletas (sétima e oitava), observa-se a tendência de redução do número de animais soropositivos ao longo do tempo.

Pérez et al. (2013) verificaram resultados semelhantes em um programa de controle da Maedi-Visna, avaliado por oito anos, em que se utilizou metodologia (testes sorológicos e segregação) similar à empregada neste estudo. $\mathrm{O}$ rebanho ovino estava inicialmente altamente infectado (66,4\%), e após o controle sorológico com o teste de ELISA de bloqueio utilizando-se a glicoproteína gp135, repetido anualmente ou duas vezes por ano, foram obtidos níveis de soroconversão baixa, menores que $2,5 \%$, após o segundo ano. Na última análise, esses autores verificaram uma taxa de incidência residual de $0,8 \%$, muito semelhante à verificada nos resultados obtidos pelo teste de WB utilizado neste trabalho $(0,9 \%)$. Outro ponto em comum desses dois trabalhos foi que, com a redução a níveis residuais de soropositividade, existiu um abrandamento dos sinais clínicos da enfermidade, o que resultou na melhora da saúde e do bem-estar do rebanho.

Ao se analisar a Fig. 1, observa-se, na sétima coleta, um crescimento no percentual de soropositivos. Isso provavelmente ocorreu devido à latência sorológica e/ou à soroconversão tardia de animais que não tiveram anticorpos suficientes para serem detectados nos testes durante as coletas anteriores ou até mesmo devido a uma infecção durante o estudo. Pérez et al. (2013) também observaram variação na incidência ao longo do programa de controle. Segundo Hanson et al. (1996), os baixos níveis de anticorpos, a soroconversão tardia e as reações soropositivas intermitentes são o grande problema para o controle dessa virose. 
Quando se avaliaram os resultados sorológicos das oito coletas, notou-se que apenas duas cabras foram reagentes no ELISA-i e não apresentaram positividade no WB. Por outro lado, todos os soropositivos na IDGA também o foram no WB, apesar de três destes não terem reagido no ELISA-i. Em algumas coletas, observou-se uma pequena discordância entre o WB e o ELISA-i.

O tempo para o animal produzir anticorpos detectáveis no teste IDGA é longo, podendo ocorrer até 18 meses após a identificação pela PCR, ou, até mesmo, pode não acontecer a detecção (Wagter et al., 1998). Rimstad et al. (1993) demonstraram que a soroconversão tardia acontece, mesmo quando são utilizados testes com sensibilidade analítica superior à da IDGA, como os testes imunoenzimáticos, por exemplo.

O rebanho continuou a apresentar incidência de animais soropositivos mesmo utilizando-se testes sorológicos mais sensíveis (ELISA-i e WB) em intervalo de tempo menor (quatro meses) que o comumente recomendado (seis meses) (Pérez et al., 2013). Esse fato fortalece a necessidade da utilização de testes moleculares diretos (como a PCR, por exemplo), aliados a testes sorológicos (Álvarez et al., 2006; Gregory et al., 2011; Konishi et al., 2011; Barquero et al., 2013). Pérez et al. (2013) também não conseguiram a erradicação dessa enfermidade, mesmo após a implementação por oito anos de um programa de controle, num total de 11 avaliações sorológicas do rebanho, e, também, indicaram a associação com testes moleculares.

Resultados discordantes entre PCR e testes sorológicos já foram descritos. Rimstad et al. (1993) demonstraram que $25 \%$ dos animais soronegativos por ELISA-i, IDGA e Western Blot foram positivos por PCR. Wagter et al. (1998), quando trabalharam com animais que faziam parte do programa de controle nacional holandês contra $\mathrm{CAEV} / \mathrm{MVV}$, observaram que oito animais soropositivos pela IDGA foram negativos por PCR.

A escolha de provas laboratoriais mais sensíveis para a implantação de programa de controle é de suma importância para detecção precoce de animais positivos. A presença de animais falsonegativos no rebanho é um dos grandes entraves para os programas de controle da CAE (Alvarez et al., 2006; Pinheiro et al., 2010). Programas de controle já foram implantados em vários países e fornecem informações importantes sobre $\mathrm{o}$ controle da enfermidade. Entretanto, ainda é difícil sua erradicação, visto que os testes têm alto custo e aquele mais utilizado (IDGA) não detecta precocemente os soropositivos (Konishi et al., 2011; Gregory et al., 2011; Pinheiro et al., 2012).

Apesar de existirem, neste estudo, técnicos qualificados e testes bastante sensíveis, os resultados revelam que as medidas rigorosas de manejo adotadas, aliadas à frequência dos testes em menores períodos, não foram suficientes para erradicar a enfermidade do plantel, mas apenas controlá-la. Em dois anos e seis meses de programa de controle, somente o WB detectou animais com anticorpos contra o CAEV em todas as coletas, e, ainda assim, esse período não foi suficiente para erradicar a doença do rebanho. O mesmo fato foi observado por Pérez et al. (2013) com o teste ELISA para o vírus da Maedi-Visna.

Ao se avaliarem os testes sorológicos utilizados no programa de controle (Tab. 2 e 3), pode-se verificar que o WB foi o teste mais sensível na detecção de animais positivos. Como o rebanho já havia se submetido a um programa de controle empregando a técnica de IDGA durante os anos de 1994 a 2008, muito provavelmente esses animais com reação imunológica mais forte em relação ao CAEV já tinham sido segregados e não eram mais detectados por testes pouco sensíveis. Esse dado corrobora os achados de Pinheiro et al. (2010), os quais verificaram que um rebanho submetido ao controle por um antígeno, que contenha uma determinada proteína específica, perde, com o tempo, a sua capacidade de diagnóstico, em virtude da retirada de todos os animais infectados que expressavam aquela proteína.

Além disso, a menor sensibilidade da IDGA, a despeito da diferença na produção de anticorpos, pode ser explicada, em parte, pelo mecanismo de interação antígeno-anticorpo. Embora os testes imunoenzimáticos requeiram a ligação de somente um simples epitopo para obter um resultado positivo, a precipitação em gel de ágar requer interações múltiplas antígeno-anticorpo (Pinheiro et al., 2006). Segundo Pinheiro et al. (2012), o WB tem a capacidade de detectar anticorpos numa diluição de até 128 vezes maior que a IDGA e 16 vezes maior que o ELISA. 
O antígeno produzido pela Embrapa Caprinos e Ovinos utilizou o vírus total e foi usado tanto para o ELISA-i quanto para o WB, e a sua concentração proteica foi de $2,53 \mathrm{mg} / \mathrm{mL}$, compatível com a observada por Castro et al. (1999) e Pinheiro et al. (2006). Zanoni et al. (1989) relataram que a utilização do vírus completo como fonte de proteínas antigênicas apresenta vantagens por reduzir resultados falsopositivos. Trabalhos com a junção de duas ou mais proteínas, principalmente de regiões diferentes do vírus, podem aumentar muito a sensibilidade do teste, como no estudo de Pérez et al. (2013).

Em virtude da similaridade antigênica entre os lentivírus de pequenos ruminantes (LVPR), explicada pela sequência de nucleotídeos conservada da região gag, que codifica os determinantes antigênicos grupo-específico da p28 (Roberson et al., 1982), existem variações nucleotídicas que podem influenciar os resultados de testes sorológicos. A sensibilidade e a confiança dos testes sorológicos não dependem somente do tipo de teste utilizado, mas podem ser influenciadas também pelo método de preparação do antígeno e pela escolha da cepa viral e dos componentes virais do antígeno mais relevantes imunologicamente (Celer Jr. et al., 1998).

Além dos fatores já mencionados, a heterogeneidade viral e o potencial da transmissão interespécie dos LVPR devem ser ponderados naqueles casos em que existe a criação consorciada de caprinos e ovinos, quando do desenvolvimento de programas de sanidade de pequenos ruminantes (Souza et al., 2012).

\section{CONCLUSÕES}

A adoção periódica de testes sorológicos de alta sensibilidade, como o WB, e a segregação de animais soropositivos nos programas de controle da CAE são importantes, pois dão o direcionamento das medidas que devem ser implementadas no rebanho. Entretanto, deve-se esquematizar uma associação entre técnicas de diagnóstico sorológico e molecular, aliadas a práticas de manejo adequadas, para fins de erradicação. Esse tipo de programa de controle exige vigilância periódica e contínua, uma vez que a interrupção do controle sorológico certamente leva a um aumento progressivo da soroprevalência, com aparecimento de casos clínicos com prejuízo da saúde e do bem-estar animal. A constatação de resultados negativos no rebanho pela IDGA e pelo ELISA-i, em duas coletas consecutivas intercaladas de 120 dias, não é garantia de que o rebanho está livre da enfermidade.

\section{AGRADECIMENTOS}

À Empresa Brasileira de Pesquisa Agropecuária - Embrapa Caprinos e Ovinos, pela concessão das condições técnicas e estruturais; à Capes, ao $\mathrm{CNPq}$, à Funcap e ao Banco do Nordeste, pelo apoio financeiro.

\section{REFERÊNCIAS}

ÁLVAREZ, V.; DALTABUIT-TEST, M.; ARRANZ, J. et al. PCR detection of colostrum-associated MaediVisna virus (MVV) infection and relationship with ELISA-antibody status in lambs. Res. Vet. Sci., v.80, p.226-234, 2006.

ANDRIOLI, A.; GOUVEIA, A.M.G.; MARTINS, A.S. et al. Fatores de risco na transmissão do lentivírus caprino pelo sêmen. Pesqui. Agropecu. Bras., v.41, p.1313-1319, 2006.

BARLOUGH, J.; EAST, N.; ROWE, J.D. et al. Double-nested polymerase chain reaction for dection of caprine arthritis-encaphalitis virus proviral DNA in blood, milk and tissues of infected goats. J. Virol. Methods, v.50, p.101-114, 1994.

BARQUERO, N.; GOMEZ-LUCIA, E.; ARJONA, A. et al. Evolution of specific antibodies and proviral DNA in milk of small ruminants infected by small ruminant lentivírus. Viruses, v.5, p.2614-2623, 2013.

CARNEIRO, F.F.D. Perdas econômicas decorrentes da artrite-encefalite caprina. 2011. 97f. Dissertação (Mestrado em Zootecnia) - Universidade Estadual Vale do Acaraú, Sobral, CE.

CASTRO, R.S.; RESENDE, M.; GOUVEIA, A.M. A labelled avidin-biotin ELISA to detect antibodies to Caprine Arthritis-encephalitis virus in goat's sera. Vet. Res. Commun., v.23, p.515-522, 1999.

CELER Jr., V.; CELER, V.; NÉMCOVÁ, H. et al. Serologic diagnosis of ovine lentiviruses by whole virus Elisa and IDGA test. Zentralbl. Vetmed Beih., v.45, p.183-188, 1998.

DAWSON, M. The Caprine Arthritis-Encephalitis syndrome. Vet. Ann., v.29, p.98-102, 1989. 
GREGORY, L.; LARA, M.C.C.S.H.; HASEGAWA, M.Y. et al. Detecção do vírus da artrite encefalite caprina em pulmão, glândula mamária, cérebro e líquido sinovial de cabras naturalmente infectadas pela técnica de nested-PCR. Med. Vet., v.5, p.7-11, 2011.

HANSON, J.; HYDBRING, E.; OLSSON, K. Along term study of goats naturally infected with caprine arthritis-encephalitis virus. Acta Vet. Scand., v.37, p.31-39, 1996.

KONISHI, M.; NAGURA, Y.; TAKEI, N. et al. Combined eradication strategy for CAE in a dairy goat farm in Japan. Small Ruminant Res., v.99, p.65-71, 2011.

LAMARA, A.; FIENI, F.; MSELLI-LAKHAL, L. et al. Efficient replication of caprine arthritisencephalitis virus in goat granulosa cells. Vírus Res., v.79, p.165-172, 2001.

MADUREIRA, K. M.; GOMES, V. Prevalência da Artrite Encefalite Caprina (CAE) em propriedades leiteiras do Estado de São Paulo. Rev. Cienc. Vet., v.5, p.86-90, 2007.

MARTÍNEZ-NAVALÓN, B.; PERIS, C.; GÓMEZ, E.A. et al. Quantitative estimation of the impact of Caprine Arthritis Encephalitis virus infection on milk production by dairy goats. Vet. J., v.197, p.311-317, 2013.

MELO, A.C.M.; FRANKE, C.R. Soroprevalência da infecção pelo vírus da Artrite Encefalite Caprina (CAEV) no rebanho de caprinos leiteiros da Grande Fortaleza, Ceará, Brasil. Cienc. Rural, v.27, p.113117, 1997.

MOURA SOBRINHO, P.A.; RAMOS, T.R.R.; FERNANDES, C.H.C. et al. Prevalência e fatores associados à infecção por lentivírus de pequenos ruminantes em caprinos no Estado do Tocantins. Ciênc. Anim. Bras., v.11, p.117-124, 2010.

PÉREZ, M.; MUÑOZ, M. J.A.; BIESCAS, E. et al. Successful Visna/maedi control in a highly infected ovine dairy flock using serologic segregation and management strategies. Prev. Vet. Med., v.112, p.423427, 2013.

PETERHANS, E.; GREENLAND, T.; BADIOLA, J. et al. Routes of transmission and consequences of small ruminant lentiviruses (SRLVs) infection and eradication schemes. Vet. Res., v.35, p.257-274, 2004.

PINHEIRO, R.R.; ANDRIOLI, A.; GOUVEIA, A.M.G. et al. Avaliação de antígenos para o diagnóstico de lentivírus em rebanho caprino sob programa de controle. Arq. Inst. Biol., v.77, p.133137, 2010.
PINHEIRO, R.R.; ANDRIOLI, A.; SIDER, L.H. et al. Lentiviroses em pequenos ruminantes: principais métodos de diagnóstico. Sobral: Embrapa, 2012. p.132. (Comunicado Técnico, n.107).

PINHEIRO, R.R.; OLORTEGUI, C.D.C.; GOUVEIA, A.M.G. et al. Desenvolvimento de dot-blot para detecção de anticorpos para o vírus da artrite encefalite caprina em caprinos. Rev. Port. Cienc. Vet., v.101, p.51-56, 2006.

RELATÓRIO de consultoria - programa de controle da artrite encefalite caprina a vírus (PCAEV-II). Sobral: Embrapa, 1996. 110p.

RIMSTAD, E.; EAST, N.E.; TORTEN, M. et al. Delayed seroconversion following naturally acquired caprine arthritis-encephalitis virus infection in goats. Am. J. Vet. Res., v.54, p.1858-1862, 1993.

ROBERSON，S.M.; MCGUIRE，T.C.; KLEVJERANDERSON, P. et al. Caprine arthritis-encephalitis virus is distinct from visna and progressive pneumonia viruses as measured by genome sequence homology. J. Virol., v.44, p.755-758, 1982.

RODRIGUES, A.S.; BRITO, R.L.L.; PINHEIRO, R.R. et al. Padronização do Elisa indireto e Western blot para o diagnóstico da artrite-encefalite caprina. Arq. Bras. Med. Vet. Zootec., v.66, p.417-424, 2014.

SALTARELLI, M.; QUERAT, G.; KONINGS, D.A.M. et al. Nucleotide sequence and transcriptional analysis of molecular clones of CAEV which generate infectious virus. Virology, v.179, p.347-364, 1990.

SOUZA, K.C.; PINHEIRO, R.R.; BRITO, R.L.L. et al. Transmission of the caprine arthritis-encephalitis virus through artificial insemination. Small Ruminant Res., v.109, p.193-198, 2013.

SOUZA, T.S.; PINHEIRO, R.R.; LIMA, C.C.V.; COSTA, J.N. Transmissão interespécie dos lentivírus de pequenos ruminantes: revisão e desafios. Acta Vet. Bras., v.6, p.23-34, 2012.

WAGTER, L.H.; JANSEN, A.; BLEUMINKPLUYM, N.M. et al. PCR detection of lentiviral gag segments DNA in the white blood cells of sheep and goats. Vet. Res. Commun., v.22, p.355-362, 1998.

ZANONI, R.; KREIG, A.; PETERHANS, E. Detection of antibodies to Caprine ArthritisEncephalitis Virus by protein G enzyme-linked immunosorbent assay and immunoblotting. J. Clin. Microbiol., v.27, p.580-582, 1989. 